\title{
ONE FUNERAL AT A TIME! WHY WE HOLD ON TO OLD IDEAS
}

\author{
Rosemary Sage, \\ School of Education, University of Buckingham
}

\begin{abstract}
This article discusses how easily we lock ourselves into established theories, which are often promoted within our formal education. They can blind us to new developments, influencing our professional practice and progress by narrowing thinking. Chomsky's theory of Universal Grammar is an example, since this paradigm has dominated teaching and learning for over 50 years. It has led to a focus on the form of language, rather than its content and use, restricting learning approaches and contributing to lower standards of UK Education when compared with other countries. The Organisation for Economic Cooperation \& Development (2016 \& 17) attributes limited value for language as a reason for the UK being near the bottom of the global league. Language development is presented within physical, mental, emotional and social aspects of communication. Competence across areas opens the mind to empathy, new experiences, continuous learning, humour, teamwork and cultural awareness. These elements together distinguish us from robots and are vital for our futures, as improved interaction of people is required for new job possibilities since machine technology is taking over routine work.
\end{abstract}

\section{INTRODUCTION}

Many of us are wedded to dated ideas and find it difficult to ditch them! Max Planck noting that academics hang on to old ways, said: 'Science progresses one funeral at a time'! This struck me when studying Speech Pathology, as Noam Chomsky (1965) has dominated teaching for the last 50 years. He promoted a 'universal grammar', equipping humans with an astonishing ability to both generate and understand infinite expressions and defined how this worked. The brain's innate sentence-generating machine would fit words into correct syntactic slots, like subjects, verbs and objects. The theory was compatible with the emerging field of computer science, as academics were anxious to embrace a computational approach to everything. It also resonated with human biology and a possibility of revealing brain underpinnings to the world's 7,000+ languages. This model has led to grammar and vocabulary-based teaching and arbitrary language assessments. 
Today, there is concern about the low levels of language and thinking amongst children (Sage, et al 2017). The response is to still hold on to old ideas and focus more strongly on teaching language form rather than content and use. We believe that studying rules, by which words change forms and combine into sentences, is key to learning, in spite of many experts advocating broader approaches.

It is difficult to reconcile Chomsky's paradigm with other languages. For example, native Australian Warlpiri has grammar elements everywhere in a sentence and is not neatly packaged as in 'universal grammar'. If you look at $U r d u$, the sentence subject is used differently to English. Spanish forms sentences without separate subjects, as in Tengo (I have), in which the person ' $\mathrm{I}$ ' is marked by 'o' at the end of the verb. The Amazon Piraha does not use recursion - the way phrases are tucked inside others to build sentences. As a speech therapist, assessing communication, there was a great deal more to consider than just innate grammar. When talking, ability to categorize (people/objects) and understand relations among things is fundamental. One must also grasp the communicative intention of others, retain, recall and integrate words, voice, gestures, manner and context clues to enable language to happen successfully. This is accompanied by social abilities to connect with others (phatics) to develop trust, coping with different views, values and attitudes positively. Since words convey only $7 \%$ of the affective meaning of a message, voice dynamics at $38 \%$ and gestures at $55 \%$ are crucial elements. Therapists focus first on these para-linguistic elements to build effective understanding and expression (Mehrabian, 1971, Sage, 2000). In development, communication comes first and grammar later, when thinking becomes 'externalised' for conversation. Language cannot exist without specifically human forms of social cognition and interaction.

\section{THE LANGUAGE SYSTEM}

Imagine a system of thousands of units, generated from a small set of matter. These units can be assembled into infinite combinations. Only a subset of these is correct in practice, but has infinite possibilities. One must grasp this language system to communicate needs, feelings and views, as well as understand those of others. The units are words, the matter is a small set of sounds, from which they are constructed and combined in sentences. Given this complexity, it is amazing that children discover the underlying structure and use it to communicate, and most do without difficulties, given right support. Studies examine language learning, comprehension and expression. How do children crack the system, finding words within the acoustic stream that produce language? How do they combine linguistic elements and determine their relationships? How do they impose grammatical structure onto input - creating a new language when none is available? Research shows 
ways in which children extract, manipulate and create the complex linguistic and social structures existing in languages.

\section{LOCATING UNITS}

Before infants can map words onto objects around them, they must determine which sound sequences represent them. They uncover units belonging to mother-tongue, from a continuous sound stream, in which words are seldom surrounded by pauses. Despite this, children successfully segment words from fluent speech at around age 8 months. How do they learn so quickly? Studies present them with artificial languages, embodying certain aspects of natural linguistic structures. Once familiar with this sample, a new one is given. Measures of surprise (duration of looking toward new sounds) assess whether an infant perceives the new sample as more of the same or different, providing insights into language acquisition (Jusczyk, 1997).

Saffran et al (2001) examined the role that statistical learning (detection of consistent sound patterns) plays in word-segmentation. Syllables (parts of a word), tend to follow one another predictably, whereas those spanning word boundaries do not. Studies found that infants detect and use the statistical properties of syllable co-occurrence to segment new words. They do not detect how frequently syllable pairs occur, but the probabilities with which one predicts another. Infants, therefore, may find word boundaries by detecting syllable-pairs with low transitional probabilities. Babes, as young as 8 months, perform these computations with only 2 minutes of exposure. Averaging from 10 languages shows language responses appear in around 200 milliseconds, the time it takes to blink! Absorbing the statistical regularities of acoustic events, infants can structure linguistic input into relevant, meaningful units. Does this extend to non-linguistic learning? They can detect probabilities with which musical tones predict one another, suggesting that the statistical learning abilities for word-segmentation may be used for tunes. Children (not adults) can track the statistical structure of sequences of absolute pitches in a tone-sequence task. Findings show that some statistical learning mechanisms are not only applied to language.

\section{COMBINING WORDS}

Identifying language words and their context meaning, is only the first step. Children have to discover how the distribution of elements, including grammatical endings ( $-s$, -ed, -ing) and function words (of, to, the) convey further meaning of an utterance. They must locate and use grammar to determine who-did-what-to-whom in sentences, as in 'Dad gave Mum the bottle', as opposed to 'Mum gave Dad the bottle'. Parsing helps comprehension, allowing assembly of sequenced elements to compute crucial, novel, relational world concepts. Adults are adept at parsing sentences for 
relational meaning - achieved as each word is perceived. By measuring eyefixation and reaction time mid-sentence, they rapidly package incoming words into likely phrases, using various sentence cues and the referential context. (Tanenhaus et al, 1995).

Moore et al (2001) examined how parsing develops. Eye movements of children age 4+ were recorded as they heard instructions to move objects. Visual analysis during speaking revealed the interpretation process. Reactions to ambiguous instructions, requiring an implicit grammatical choice, were revealed, as in 'Tap the doll with the stick'. The phrase 'with the stick 'can link to the verb 'tap', indicating how to do this, or to the noun 'doll', showing which one to tap. Adults rely on the referential context when making choices, selecting what is most appropriate. What do children choose? This depends on linguistic cues in the utterance. They decipher 'with the stick' as how to carry out the action, when the verb like 'tap' is an instrument. In contrast, they interpret this same phrase as picking out a specific doll, when the verb (e.g. feel) does not mention an instrument. Infants employ probable cues to assemble syllables into words and older children package words into phrases, using similar distributional evidence regarding these larger elements. Further experience is necessary to detect when phrases are likely in given referential settings. Trueswell et al (1999) found that by age 8, children parse ambiguous phrases in a context-contingent manner.

\section{LANGUAGE CREATION}

\section{Understanding Informal and Formal communication Consider 2 communication forms:}

1. Context: A supermarket. A conversation between Rosie \& the Shop Manager.

Rosie: Excuse me - have you any more of these? This seems the only one left.

Manager: Oh! I'll just check. Chris, can you see if we have any more? ... I'm so sorry - this is the last one. We'll have our next delivery on Thursday.

2. Context: Report on a supermarket visit to buy flour for bread-making.

Having been away for a week, I noticed on return that we had run out of bread-flour. We make our own bread, so I rushed to the supermarket, in the next village, to buy some. On searching the shelves, I could only find 1 bag, so approached the till and asked the manager if they had more stock. She called an assistant (Chris), who went to look but returned to say the flour had gone. It is popular and goes as soon as hitting the shelves. A delivery in 3 days meant stocks would be in on Thursday. I thanked the staff, paid for the last bag and resolved to visit the supermarket early on delivery day.

Although distributional analyses enable children to break into language words and phrases, many higher linguistic functions cannot be acquired from statistics alone. Children must discover what generates an infinite set with only a finite sample. They evidently possess additional cognitive and social 
abilities, enabling them to organize their language appropriately without explicit guidance. These competencies arise from informal conversation experiences, developing the 5 essential moves (below). Meaning comes mainly from the context in informal face-to-face exchanges, before able to manage formal language events dependent on intuitive competencies (infer, refer, confer). Examples are now shown in the table above.

\section{WHAT DO YOU NOTICE ABOUT BOTH EXCHANGES?}

The first is unplanned and informal, relying on context for understanding. It is impossible to establish meaning from words alone, which derives from place \& props (shopping conventions, bag of flour, shop layout etc.). Communication is implicit, from shared understanding.

The second formally reports events away from the context. It could be spoken or written, as at this literate level of thinking and expressing, the organisation of ideas is key to understanding word sequences. Language is explicit for picturing the scene - locating context, characters, actions, reactions and results, known as narrative thinking and structure. It is impossible to report all details, so comprehension relies on ability to infer, refer \& cohere information from many sources. What are the information \& opinion gaps? One must imagine how bread is made (by hand or machine); character ages; sex of assistant (Chris could be male/female) and manner of the exchange. We must visualise the scene for understanding, recalling memories of similar events and know who is referred to from words she, both \& us. Assembling information (cohere) provides the story-gist for retention and review.

Narratives are learnt in formal talk, like meal-times, when people review telling, retelling, reporting, explaining and discussing events. Acquiring literate, informative talk is the step into the secondary languages of literacy \& numeracy, depending on conceptual, declarative \& procedural knowledge and causal connections learnt from speaking. Studies show that family-eating is now rare, happening on the hoof or in front of the television (Sage, 2000). Frenetic lifestyles mean less opportunity for formal talk. We eat fewer meals together, watch television/use computers rather than converse, with visual images dominating, so do not gain primary understanding from words. Habits of communicating largely by email, chat rooms and texts mean we are not experiencing the nuances of exchanges, from non-verbal sources, giving words affective meaning. Lack of face-to-face exchanges not only restrict sharing ideas, reviewing and refining thoughts, but hamper full understanding of events, leading to ineffective judgments and decision-making. Doctors attribute increasing mental problems to a decline in extended talk and its role in helping us cope with issues, by discussing feelings to gain fresh perspectives. For interpersonal exchanges \& understanding teacher monologue, the following moves and narrative development must be in place: 
CHECK LIST OF 5 CONVERSATION MOVES: Can the student.....

1. Answer a closed 'what, who, where, when' question demanding a specific response?

2. Contribute an idea (even if not entirely appropriate) showing turn-taking ability?

3. Listen \& demonstrate maintenance moves (like eye contact for $75 \%$ of time smiling/nodding)

4. Answer an open 'how' or 'why' question demanding an explanation?

5. Initiate a new idea in conversation that fits with the topic under discussion?

If moves 3-5 are seen, a spoken/written narrative event can be followed. Listening attention (3), with forward posture and eye-contact, suggests concentration and cooperation. If attention wanders, it shows boredom or inability to follow the discourse. Answering open questions (4) requires expression of cause \& effect and linking events. 'Esme, why are you wearing your coat? (Because it's cold today). This schema assembles talk/text. Initiating a new idea (5) reveals topics connect coherently, demanding an overview and understanding that parts fit to make a whole. This 'top-down' \& 'bottom-up' process is vital to complete tasks. Take reading: getting the story gist is a 'top-down' process, as is telling/writing a report. Phonics is a 'bottom-up' one, fixing on elements - synthesizing sounds into words \& sentences. This can proceed from concrete to abstract (reading \& retelling a story) or vice-versa, when building sounds into words. It is analogous to inductive thinking, gathering information until a conclusion is drawn from facts. 'Top-down' processing equals deductive thinking, with the pattern sought and details checking a hypothesis, showing links between thinking \& language structures. Conversation moves must be in place, for shifting into formal talk, but are often missing.

\section{A Sequence of Narrative Development from Medical Research Council Research} * (Sage, 2000)

\begin{tabular}{|l|l|l|}
\hline Goal & Idea development & Description \\
\hline 1 & Record & Produce a range of ideas \\
\hline 2 & Recite & Arrange simple ideas coherently \\
\hline 3 & Refer & Compare ideas \\
\hline 4 & Replay & Sequence ideas in time \\
\hline 5 & Recount & Explain ideas - why? How? \\
\hline 6 & Report & Introduce, discuss describe, evaluate ideas \\
\hline 7 & Relate & Setting, events, actions, results, reactions \\
\hline
\end{tabular}

Research shows that many students leave education without achieving Levels 5-7, affecting ability to follow instructions, explain procedures and discuss issues in their job roles (Sage, 2000, 2017). Competencies diminish with age and may be biologically based (Pinker, 1994). Experimental efforts to isolate them are difficult, as languages were acquired before testing, so input to children already has biases. It is difficult to determine whether a 
particular linguistic element observed is inborn or derived. This is seen in situations where language is impoverished. Can children deprived of exposure to rich language build a structured one? An example is Nicaraguan Sign Language, appearing among deaf children in special education. They could not hear the Spanish spoken around them and no developed sign language was available. Children responded by producing gestures, containing grammatical regularities not found in their input, so created a new, natural sign language. This continues to develop and change as new generations enter school and learn from older peers. There is measurable discrepancy between input to which each arrival set was exposed and language acquired, evident in comparisons between group 1 (now adults) and 2 (now teenagers) (Senghas, 2001).

A development is expression of semantic roles, to indicate who-did-whatto-whom in a situation (as in the difference between girl pushes boy \& boy pushes girl). Group 1 invented signs for things they needed to talk about (girl, boy, pushes, falls, give etc.) and developed ways to string them into sentences. To describe events, they would name each participant followed by their role, such as girl push boy fall, or boy give girl receive. Group 2 added more structure. Over time, not only was the sign order important, it also mattered where \& how it was produced. Once the boy \& girl were mentioned - push produced to one side meant the girl and to the other - the boy. Children developed spatial devices to indicate semantic roles, typical of sign languages. A use of such constructions is still evident among Nicaraguan adolescents but not adults. Without context cues, adolescents give a narrower interpretation than intended by adults, despite signing representing their initial input. Findings show that children apply their own organizational biases to input that is not richly structured. Even when cues are absent from context, they can use inborn abilities to produce a common, community language.

\section{LANGUAGE DEVELOPMENT}

Examples of language learning, processing and production represent developments between birth and maturity. Children discover the sounds (or gestures) of their language; learn their combination into longer sequences and map these on to meaning. Such simultaneous processes require integration of physical, mental, emotional \& social abilities to crack the communication code. Despite complexity (beyond present computers), children solve linguistic puzzles, surpassing their input when it lacks the expected structure. However, there is much research to show that children do not readily assemble large chunks of talk or text for formal communication purposes without formal teaching (Sage et al, 2000, 2017).

Many methods are used to uncover what underlies language development. Before infants utter their first word, early mechanisms are examined by recording subtle responses to new sound combinations. Once they link words, 
studies using real-time measures of language-processing reveal ways linguistic \& non-linguistic information integrate for listening. When children are faced with minimal language exposure it shows the extent of inborn learning and effect on language creation and change. As ways of probing minds are developed \& findings integrated, they will reveal learning processes more clearly. Studies manipulating the CREB gene enhance emotional memory, showing how this occurs, by encoding a protein regulating other genes needed for this. The strength of synaptic connections, critical for retention and recall of jlanguage and information, is increased and this knowledge assists teaching (Silva, 2018).

\section{THE PRESENT PROBLEM}

We live in a country where many languages intermix. In large cities, English now appears a minority means of communication. In a Leicester school, 234 languages are spoken, with students grouped with their mothertongue peers at break-time. There are 7-10,000 languages across the world and over 22,000 varieties (Voegelin's World Classification Index). Now problems in understanding others exist and teachers find this a stress in diverse classrooms - transmitting information to many cultures with much lost in translation (Sage, 2018).

Legend has it there was originally only one language. The people of Babylon decided to build The Tower of Babel and establish their name worldwide. In Genesis 11.6, it states that for those speaking the same language nothing is impossible. However, God considered that this tower was unacceptable and by causing people to speak different languages it would make it difficult to communicate, cooperate and collaborate. Language reflects culture, custom and a particular world-view. The French word 'boulangerie' means 'bakery' and in France is a community's social centre in a way English counterparts are not. In Burundi, language divides and rules. Older people precede younger with males before females. The latter are not allowed to speak in company unless directly approached. Speaking well shows good breeding, so boys have formal training in how to communicate in different situations. Girls are taught to listen, for repeating accurately conversations they have heard. Thus, language use is intricately bound up with the values, views and attitudes of particular ethnic groups and it is imperative to understand intercultural communication patterns for successful relationships.

In China, there is a popular saying: 'We are separated by a blade of grass' meaning people cannot communicate because of speaking in different ways. A Romanised alphabet (Pin Yin) is now taught to everyone, along with a standard language (Putonghua). In Britain, we abandoned the teaching of Standard English in the 1970s, because it was regarded as elitist. Local dialects are encouraged, but School Inspectors note that students find 
difficulty in understanding teachers if using an unfamiliar way of speaking. Leicester University research found that communication with teachers was the greatest problem for students (Sage, 2000).

\section{MINIMAL LANGUAGE}

Toki Pona is a constructed rather than a natural language, first published on the web in 2001 and as a book: The Language of Good (2014). Sonja Lang, a linguist, designed this minimal language, inspired by Taoist philosophy, shaping thoughts of users in Zen-like fashion. Like a pidgin, it focuses on simple, universal concepts and elements. It expresses maximal meaning with minimal complexity, with 14 phonemes and 120 root words, but is not an international auxiliary language, allowing people of different tongues to communicate. An example is 'jan' (person) combining with 'utala' (fight) to represent 'soldier'. It is a fine example of how to economize on words, as English now has reached over 1 million in common use (Sage, 2009). It takes only 4 hours to learn Toki Pona and I tried this once, but with no opportunities for use, it was quickly forgotten! We have to consider the issue of communicating more effectively in Britain, as our liberal multicultural policies are preventing a common language use - separating rather than bringing people together harmoniously.

\section{SUMMARY}

When the Chomsky paradigm was developed, it was a radical break from preoccupations with language origins (bow-wow, pooh-pooh, ding-dong, yohe-ho, ta-ta \& la-la theories)**. As it promoted a universal grammar, critics have drawn attention to the cognitive and social complexities in becoming competent at processing and producing language, but the theory has remained dominant and blinded us to other aspects of interpersonal exchanges. An upside of present mobility is that we have become more aware of world languages - their similarities and differences - and how they change to reflect the culture and customs of speakers. It is easy to hang on to familiar ideas but the world requires us to be open-minded and willing to alter views in line with emerging, new knowledge and understanding about human development.

Language study plays a central role in diverse disciplines, from literature to artificial intelligence and linguistics itself. It is a creation of culture, developing from social cognition and a capacity to use symbols representing things and experiences. If you know what language is and how it functions, you comprehend more about human nature and how information processing occurs for learning. We need this understanding at a time when we are losing ability to talk effectively with one another but require improved communication for new work roles. 
Darth Vader, the Sith Lord, issued a message: change your accent if you want a role in a Star Wars film. This started a heated, media debate on how we speak dictates the kind of person we are and what we can achieve in life, both personally and economically. Today, many varieties of a language are spoken, which are rapidly increasing with the constant movements of people across national boundaries and the absorption of new words and pronunciations.

Language is our most important communicative tool and we must keep abreast of new knowledge about this process. Teachers need to assess student cognitive \& linguistic development, for delivering information that everyone can understand. Linguistic competencies are paramount - opening minds to empathy, new experiences, continuous learning, humour, teamwork and cultural awareness. Together these distinguish us from robots and are vital for survival, but surveys suggest an urgent need for improvement (Egglestone et al, 2018). We must not be imprisoned in our minds, confined by narrow views and suspicious of others who speak and think differently. Our primal competition for power, control and increasingly scarce resources suggests there is a long way to go.

\section{NOTES}

*The COGS developed as learners often have to perform at a higher language level than acquired \& so struggle to process/express narrative events. It assists narrative thinking, understanding \& expression over 10 levels for pre-schoolers to post-graduates. Levels are not tied to ages, using zones of potential development. Narrative thinking develops over 7 levels with 8, 9, 10 - targeting professional demands, within principles of clarity, content, convention \& conduct, taking account of individual intelligence, attitude, opportunity \& personality.

**Bow-wow- emerging from cries of beasts/birds

Pooh-pooh - emerging from emotional exclamations - pain/pleasure etc.

Ding-dong - reflecting the vibrating resonance of things

Yo-he-ho - emerging from rhythmic chants accompanying actions

Ta-ta - tongue movements mimicking gestures

La-la - emerging from songs

\section{REFERENCES}

Chomsky, N. (1965) Aspects of a Theory of Syntax. Cambridge, MA: MIT Press.

Egglestone C., Stevens, C., Jones, E.\& Aldridge, F. (2018) Adult Participation in Learning Survey 2017. Learningandwork.org.

Hughes E., Hughes M., Greenhill A., Senghas A., Coppola M., Newport E. \& Supalla T. (1997) in Proceedings of the 21st Annual Boston University 
Conference on Language Development. Eds. Hughes E., Hughes M., Greenhill A. Boston: Cascadilla p. 550-561.

Jusczyk, P. (1997) The Discovery of Spoken Language. Cambridge, MA: MIT Press.

Mehrabian, A. (1971) Silent Messages. Belmont, California: Wadsworth.

Moore J., Stenning K., Snedeker J., Thorpe K. \& Trueswell J. (2001) in

Proceedings of the 23rd Annual Conference of the Cognitive Science

Society, Eds. Moore J., Stenning K. Hillsdale, NJ: Earlbaum, pp 964-969.

OECD Reports (2016 \& 2017) The Development Cooperation \& Education at

a Glance.oecd.org/education.

Pinker S. (1994) The Language Instinct. New York: Morrow

Saffran, J. \& Griepentrog, G. Dev Psychol 37:74-85, pmid: 11206435.

Sage, R. (2000) Class Talk. London: Bloomsbury.

Sage, R. (2009) Hitting the Million Word Jackpot: English as the Common International Language. Key Speech: The International Conference on Communication, Poland, 2009 Instytut Psychologii, Wydział Humanistyczny Uniwersytetu Szczecińskiego.

Sage, R. (2017) Ed. Paradoxes in Education. Rotterdam, Boston, Taipei: SENSE Int. Pub.

Sage, R. (2018) Teachers Talking Tough on Tensions. Centre for Educational Development. University of Buckingham website.

Senghas A. \& Coppola M. (2001) Psychol Sci 12:323-328, pmid: 11476100.

Silva, A. (2018) Our Memory's Intricate Web. Scientific Revolutions in Science. SM Specials Vol. 27. No. 3. New York: Scientific American.

Tanenhaus M., Spivey-Knowlton M., Eberhard K. \& Sedivy J. (1995) Science 268:1632-1634, pmid:7777863.

Trueswell J., Sekerina I., Hill N. \& Logrip M. (1999) Cognition 73:89-134. 